\title{
Mosaico de Purpurina: revisitando a História do Movimento LGBT no Brasil
} Mosaic of Sequins: revisiting the History of the LGBT Movement in Brazil Mosaico de Purpurina: revisitando la Historia del Movimiento LGBT en Brasil

\section{Remom Matheus Bortolozzi $i^{1, a}$}

remombortolozzi@gmail.com | https://orcid.org/0000-0001-5606-6736

${ }^{1}$ Universidade de São Paulo, Departamento de Medicina Preventiva. São Paulo, SP, Brasil.

a Mestrado em Educação pela Universidade de Brasília.

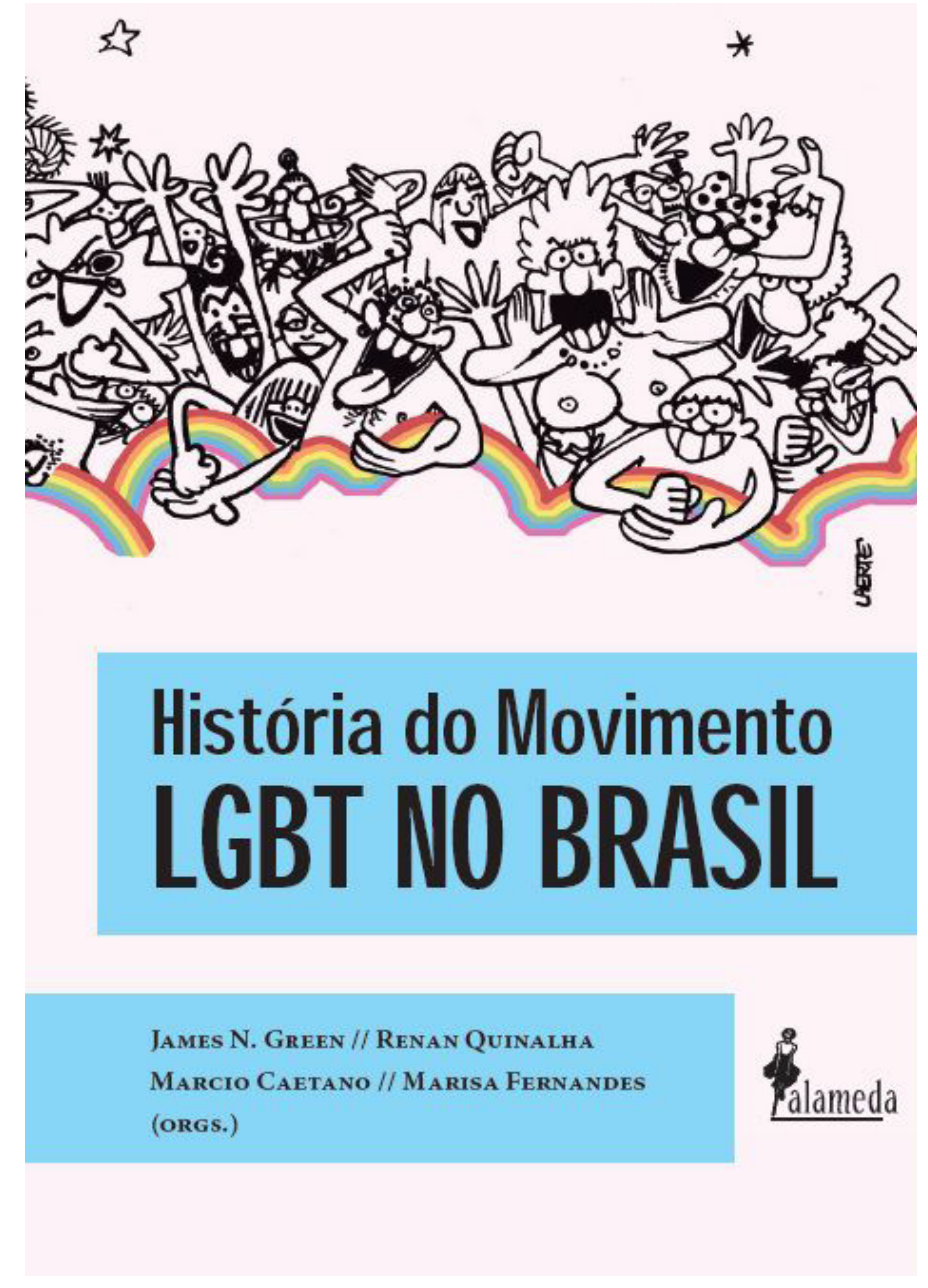

Palavras-chave: Sexualidade; Gêneros; Movimento LGBT; Memória; Direitos humanos.

Keywords: Sexuality; Genders; LGBT Movement; Memory; Human rights.

Palabras clave: Sexualidad; Géneros; Movimiento LGBT; Memoria; Derechos humanos. 
Obra resenhada: Green J, Quinalha R, Caetano, M, Fernandes M, organizadores. História do Movimento LGBT no Brasil. São Paulo: Alameda Casa Editorial; 2018. 536 p. ISBN: 978-85-7939-582-6.

Declaração de conflito de interesses: não há.

Agradecimentos/Contribuições adicionais: não há.

Histórico do artigo: submetido: 24 abr. 2019 | aceito: 28 maio 2019 | publicado: 12 set. 2019.

Apresentação anterior: não houve.

Licença CC BY-NC atribuição não comercial. Com essa licença é permitido acessar, baixar (download), copiar, imprimir, compartilhar, reutilizar e distribuir os artigos, desde que para uso não comercial e com a citação da fonte, conferindo os devidos créditos de autoria e menção à Reciis. Nesses casos, nenhuma permissão é necessária por parte dos autores ou dos editores.

História e memória tornaram-se importantes instrumentos políticos para os movimentos LGBT de diversos países. Embora ainda recente no Brasili, a temática obteve há décadas espaço de aprofundamento crítico na cena acadêmica internacional. Em especial, teve singular importância na produção acerca das respostas das comunidades LGBT à epidemia de HIV/aids nos anos de 1980-1990 e na criação de políticas de memória. Esse período não apenas acompanhou a perda sistemática de vidas LGBT, em decorrência da epidemia social intensificada pelo estigma, discriminação e violência, como também ocorreu num cenário de crise econômica, acompanhada por uma contra onda conservadora que veio em oposição às políticas progressistas de libertação sexual dos anos anteriores. Dentro de um contexto de políticas sexuais moralmente conservadoras, a própria categoria de sexualidade precisou ser revista tanto por ativistas homossexuais como pelas feministas².

Nesse cenário que apresenta diversas analogias ao atual, atos públicos em favor da memória de pessoas LGBT vítimas da epidemia da aids, como vigílias, construções de monumentos e de memoriais, como o AIDS Memorial Quilt, em 1987 (confecção de quilométricas colchas com pequenos retalhos de memórias das diversas pessoas que faleceram em decorrência do vírus), serviram para visibilizar o caráter coletivo e social da epidemia, assim como para ajudar a dar forma às identidades desses grupos ${ }^{3}$. Ao analisar as respostas comunitárias à epidemia, Capozzola ${ }^{4}$ identificou dois elementos inter-relacionados no processo de formação dessa memória: o comemorativo e o monumental. O comemorativo diz respeito, em culturas ocidentais, ao registro, testemunho ou documentação do perecimento de pessoas, ou do tempo percorrido entre a perda e o momento atual. A função monumental da memória está em interpretar a perda ou a passagem do tempo como material de aspiração para posteridade, inserindo-a, assim, em uma política contemporânea e futura.

A partir dessa ânsia que as pessoas possuem de registrar, documentar e comemorar para evitar o esquecimento coletivo em tempos de retrocessos e violações de direitos, a memória e a escrita da história redigida pelos próprios membros das comunidades LGBT tornaram-se um fazer político. Frente a um complexo cenário brasileiro de instabilidade política, com diversos conflitos sociais derivados do sucessivo avanço de um conservadorismo e de suas políticas morais, de um golpe jurídico-parlamentar-empresarial e de uma polarização acentuada nas eleições gerais, o livro 'A História do Movimento LGBT no Brasil', organizado por James Green, Renan Quinalha, Marcio Caetano e Marisa Fernandes, opta por abordar o

\footnotetext{
i No país, esse debate ganhou força na última década, em especial na relação entre memória e justiça, após a abertura dos arquivos da ditadura militar brasileira, período marcante em violações de direitos humanos por parte do Estado e com violações específicas às então comunidades homossexuais, criando espaço para o debate sobre o direito à verdade e a uma justiça de transição'.
} 
conceito de comemoração como enfrentamento. Publicada em 2018, a obra celebra os 40 anos do que hoje se nomeia 'movimento LGBT brasileiro', reconhecendo a importância da história política enquanto fundamental para um balanço crítico das estratégias de luta, de vitórias e dos atuais desafios.

Fundamentando-se na sociologia política e indo de acordo com uma vasta bibliografia na área ${ }^{5-8}$, a obra estabelece o ano de 1978 como marco inaugural para o movimento LGBT brasileiro, destacando o início do jornal mensal Lampião da Esquina enquanto primeira publicação da imprensa alternativa de circulação nacional, com caráter político e escrito por homossexuais para homossexuais, além da fundação do Grupo de Afirmação Homossexual - Somos (SP), como coletivo organizado pioneiro na mobilização de homossexuais em torno de pautas que seriam base para a luta de direitos e na articulação do Movimento Homossexual Brasileiro (MHB). Embora não se debruce sobre o período pregresso, em sua apresentação, a obra alerta para os riscos dos mitos fundacionais da história, que acabam por eclipsar ações políticas coletivas anteriores, abordadas por um conjunto de pesquisas históricas que enfocam o 'protoativismo' como forma mais complexa de compreender a formação do Movimento Homossexual Brasileiro, ${ }^{90}$.

Cabe ressaltar que o Lampião da Esquina e o grupo Somos (SP) tiveram tamanha importância para a história política LGBT brasileira que, mesmo com um curto período de cinco anos (1978 a 1983), inspiraram um conjunto de militantes homossexuais a escreverem a memória desse momento. A fim de estabelecer uma escrita de textos pioneiros confeccionados por homossexuais sobre a história política homossexual brasileira, as entidades trouxeram relatos de organizações, publicações, documentos e eventos do período. Embora encontremos alguns textos anteriores que abordem a história social da homossexualidade no Brasil, mesmo antes da publicação do Lampião da Esquina, como é o caso de 'O homossexual brasileiro nas últimas três décadas', de Daniel Franco ${ }^{11}$, foi na década de 1980 que eclodiu a produção de uma história política homossexual contada por pessoas da comunidade. Dentre os ensaios, podemos destacar: 'O Movimento Homossexual Organizado - Esse Quase desconhecido', de Leila Míccolis' ${ }^{12}$; 'GALF: 4 anos de atuação', presente no editorial do terceiro volume do boletim ChanacomChana ${ }^{13}$; 'Movimento Homossexual', de Rita Colaço ${ }^{14}$; além das duas obras pioneiras de maior fôlego investigativo para a história social e política da homossexualidade no Brasil: 'Devassos no Paraíso', de João Silvério Trevisan ${ }^{5}$ e 'O Lesbianismo no Brasil', de Luiz Mott ${ }^{15}$.

Rita Colaço, em depoimento ao autor, afirma que o estopim para a produção de seu ensaio foi o encerramento da publicação do Jornal Lampião da Esquina e o final do Grupo de Afirmação Homossexual - Somos, em 1983. Conforme a historiadora e ativista LGBT, esses importantes produtores e difusores da cultura e da política homossexual brasileira estabeleceram um sentimento coletivo que ganhou extensão no país, produzindo um clima comunitário que permitiu não apenas um sentimento de pertencimento e autorreconhecimento às diversas pessoas que viviam suas sexualidades e gêneros de forma isolada, mas também o fortalecimento e visibilidade dos, e das, homossexuais enquanto grupo político. Com o término da publicação e das atividades do grupo, pairava no ar o medo de que as conquistas do período anterior pudessem ser perdidas e esquecidas. Vale ressaltar que esse período coincide com a eclosão da aids na mídia brasileira, noticiada como câncer ou peste gay, concomitante ao aumento da violência e assassinato de homossexuais que persistiram ao longo dos anos 1980, notavelmente retratado no documentário Temporada de Caça (1988), de Rita Moreira ${ }^{16}$. Esse período, altamente circunscrito pelo estigma e discriminação, impôs um reordenamento ao movimento homossexual.

Esse conjunto de textos, com toda certeza, não registrou de formal integral a história política homossexual brasileira do período, mas se guiou em outro sentido. O olhar se orientava pela busca de fragmentos ou "trapos", como nomeia Trevisan ${ }^{17}$, das produções homossexuais e como, por meio desses estilhaços de nossa cultura, era possível narrar o que houve e analisar aquele momento histórico. Essa metodologia de procurar, a partir de fragmentos, novas formas de recontar a história, via narrativas historicamente apagadas, silenciadas e subalternizadas, especialmente as LGBT, compondo assim um quadro mais complexo para 
pensar os desafios do presente, é nomeada e proposta por Alvarez Jr. ${ }^{19}$ como "Finding sequins in the rubble", ou, em livre tradução, "achar purpurinas nos escombros". Seguindo o legado dessas pioneiras produções, a obra 'História do Movimento LGBT no Brasil' se posiciona de forma semelhante, ao buscar compor um complexo mosaico do que se reconhece hoje como movimento LGBT, por meio da reconstrução de alguns temas e momentos privilegiados, porém sem pretender dar conta da totalidade de uma história política ou social das homossexualidades ou das transgeneridades no Brasil.

A partir do mosaico diverso de textos que o livro apresenta, outra característica metodológica é perceptível: a pluralidade de vozes que narram essa história. Conforme nos mostram outras produções sobre a memória LGBT, como o trabalho de Ramírez ${ }^{19}$ acerca da memória da epidemia de HIV/aids nos Estados Unidos, a memória pública sempre é parcial e comumente desconsidera complexidades interseccionais como raça, diversidade de gênero, nacionalidade, classe, entre outros determinantes sociais da diferença. Dentro da coletânea da História do Movimento LGBT no Brasil encontramos essa diversidade, com presença de autoras e autores das múltiplas siglas identitárias, tanto de identidades sexuais como de gênero, de diversas raças e regiões do Brasil.

No que tange ao esqueleto dessa obra, elencamos quatro núcleos que parecem aglutinar o sequenciamento dos textos presentes no sumário. Os primeiros textos da coletânea gravitam em torno de um momento de liberação e afirmação do movimento homossexual, analisando as políticas sexuais de Estado em contexto de ditadura militar brasileira, repressão policial, noticiamento midiático, espaços de sociabilidade e convivência dessas homossexualidades e resistências em grupos organizados, especificamente trazendo análise das experiências do Somos (SP), Grupo de Afirmação Lésbica Feminista (GALF) e Grupo de Atuação e Afirmação Gay (GAAG) de Duque de Caxias. O segundo bloco de textos se debruça em um período posterior, já de redemocratização e de estabelecimento de um movimento que progressivamente se construiu na defesa de direitos homossexuais, trazendo grupos como o Triângulo Rosa (RJ) e o Grupo Gay da Bahia (GGB), além do aparecimento das pautas homossexuais nas eleições e o contexto de mobilização frente à epidemia da aids. $\mathrm{O}$ terceiro conjunto de textos gravita em torno das múltiplas identidades e de suas especificidades, debruçandose sobre o movimento de lésbicas negras, travestis, mulheres e homens trans, além do surgimento das Paradas do Orgulho LGBT no Brasil. Por fim, o último bloco se foca no movimento LGBT contemporâneo, abordando o espaço do fazer político institucional, trazendo reflexões sobre a participação social, a mobilização judicial por direitos, negociações e tensões do movimento e sua posição estratégica na atual arena política brasileira. Nesse mesmo bloco, também são debatidas as mobilizações político epistêmicas dentro da área da produção do conhecimento, com a formação da Associação Brasileira de Estudos em Homocultura (ABEH) e da investigação dos estudos queer, bem como sua relação com o movimento.

A partir dos 30 textos presentes na coletânea, podemos construir um panorama amplo das diversas mutações, mobilizações, repertórios, estratégias e oportunidades desenvolvidas pelo movimento LGBT brasileiro nas últimas quatro décadas. Ao mesmo tempo em que a obra comemora os 40 anos do movimento LGBT brasileiro, ela nos convida, em sua apresentação, a reavaliar o presente a partir desta história política LGBT brasileira, subindo nos ombros de nossas antepassadas por meio desse legado comunitário. Através do itinerário de leitura, faz-se o desafio de análise do movimento LGBT contemporâneo, especialmente em uma conjuntura política tão ambígua, na qual, de um lado, há frentes conservadoras de políticas que censuram o debate sobre sexualidade e gênero nas escolas, vetam produções culturais, como peças e exposições, que abordem a temática, desmontam políticas de saúde de HIV/aids e de saúde para pessoas trans e trazem novamente à cena as terapias psicológicas de 'reorientação sexual'; e, por outro lado, há resistências e avanços significativos, como a equiparação da homofobia com a lei de racismo, a garantia do direito de identidade de gênero e o casamento civil entre pessoas do mesmo sexo. Talvez, por meio desse balanço, possamos não apenas avaliar os limites e possibilidades do movimento, mas também tornar essa memória viva, monumentalizada, para que possa ser farol na luta pelos direitos humanos e pela democracia. 


\section{Referências}

1. Green J, Quinalha R. Ditadura e homossexualidades: repressão, resistências e a busca da verdade. São Carlos: EdUFScar; 2014.

2. Rubin G. Pensando sobre sexo: notas para uma teoria radical da política da sexualidade. [citado em 2019 jul. 22]. Disponível em: https://repositorio.ufsc.br/xmlui/handle/123456789/1582

3. Rand EJ. Repeated remembrance: commemorating the AIDS quilt and resuscitating the mourned subject. Rhetoric \& Public Affairs. 2007;10(4):655-679.

4. Capozzola C. A very American epidemic: memory politics and identity politics in the AIDS Memorial Quilt, 1985-1993. Radical History Review. 2002:82:91-109.

5. Trevisan JS. Devassos no Paraíso: a homossexualidade no Brasil, da colônia até à atualidade. São Paulo: Max Limonad; 1986.

6. Green J. Além do carnaval: a homossexualidade masculina no Brasil do século XX. São Paulo: Unesp; 2000.

7. Simões JA, Facchini R. Na trilha do arco-íris: do movimento homossexual ao LGBT. São Paulo: Perseu Abramo; 2009.

8. Figari C. @s Outr@s Cariocas: Interpelações, experiências e identidades homoeróticas no Rio de Janeiro Séculos XVII ao XX. Belo Horizonte: Editora UFMG; 2007.

9. Rodrigues RCC. De Daniele a Chrysostomo: quando travestis, bonecas e homossexuais entram em cena. 2012. [Tese]. Niterói: Universidade Federal Fluminense; 2012. 372 p.

10. Morando Queiroz LG. Vestígios de protoativismo LGBTQIA em Belo Horizonte (1950 -1996). Rebeh. 2018 (citado 2019 abr. 25);1(04):62-76. Disponível em: http://www.revistas.unilab.edu.br/index.php/rebeh/ article/view/164

11. Franco D. O homossexual brasileiro nas últimas três décadas. Jornal do gay (Círculo Corydon). 1978.

12. Míccolis L. O movimento homossexual organizado - esse quase desconhecido. In: Míccolis L, Daniel H organizadores. Jacarés e Lobisomens: dois ensaios sobre a homossexualidade. Rio de Janeiro: Achiamé; 1983. p. $96-120$.

13. GALF: 4 anos de atuação. Chanacomchana (Ed. 3). 1983:5.

14. Colaço R. Movimento Homossexual. In: Colaço R, organizadores. Uma conversa informal sobre o homossexualismo. Rio de Janeiro: El'Art Gráfica; 1984. p. 57-66.

15. Mott L. O Lesbianismo no Brasil. Porto Alegre: Mercado Aberto; 1987.

16. Moreira R, diretora. Temporada de Caça [filme]. São Paulo; 1988 [citado em 2019 jul. 18]. 24:06 min. Disponível em: https://www.youtube.com/watch?v=rjan Yd0C5g

17. Trevisan JS. Paraíso perdido, paraíso reencontrado. In: Trevisan JS. Devassos no Paraíso: a homossexualidade no Brasil, da colônia à atualidade. 4. ed. Rio de Janeiro: Record, 2000. p. 429-69.

18. Alvarez Jr. EF. Space, identity, and memory in queer brown Los Angeles: finding sequins in the rubble. [Tese]. Santa Barbara: Universidade da Califórnia; 2015. 396 p.

19. Ramirez HNR. Gay Latino histories/dying to be remembered: Aids obituaries, public memory, and the queer Latino archive. In: Pérez GM, Guridy F, Burgos A. organizadores. Beyond El Barrio: everyday life in Latina/o America. New York: NYU Press, 2010. p. 103-128. 